\title{
Dynamic Influence of Maternal and Pup Traits on Maternal Care during Lactation in an Income Breeder, the Antarctic Fur Seal
}

\author{
Birgitte I. McDonald ${ }^{1, *}$ \\ Michael E. Goebel ${ }^{2}$ \\ Daniel E. Crocker ${ }^{3}$ \\ Daniel P. Costa ${ }^{1}$ \\ ${ }^{1}$ Department of Ecology and Evolutionary Biology, Long \\ Marine Laboratory, 100 Shaffer Road, University of \\ California, Santa Cruz, California 95060; ${ }^{2}$ Antarctic \\ Ecosystem Research Division, National Oceanic and \\ Atmospheric Administration/National Marine Fisheries \\ Service/Southwest Fisheries Science Center, La Jolla, \\ California 92038; ${ }^{3}$ Department of Biology, Sonoma State \\ University, 1801 East Cotati Avenue, Rohnert Park, \\ California 94928
}

Accepted 2/19/2012; Electronically Published 4/6/2012

\begin{abstract}
Life-history theory predicts that selection will favor optimal levels of parental effort that balance benefits of current reproduction with costs to survival and future reproduction. The optimal level of effort depends on parental traits, offspring traits, and provisioning strategy. Additionally, how these factors influence effort may differ depending on the stage of reproduction. The relative importance of maternal and offspring traits on energy allocation to offspring was investigated in known-age Antarctic fur seals Arctocephalus gazella across four stages of reproduction, using birth mass and milk-consumption measurements. Maternal traits were important during three of the four stages investigated, with larger females giving birth to larger pups and investing more in pups during perinatal and molt stages. Pup mass influenced maternal effort during the premolt stage, and provisioning strategy influenced postnatal maternal effort at all stages. Energy provided to the offspring during an attendance visit was positively related to the duration of the foraging-trip/visit cycle; however, when investment was controlled for trip/visit cycle duration, the overall rate of energy transfer was similar across trip durations. In addition to strong effects of maternal mass, pup traits affected energy allocation, suggesting that pup demand is important in determining maternal care. These findings emphasize the importance of con-
\end{abstract}

\footnotetext{
*Corresponding author. Present address: Scripps Institute of Oceanography, Center for Marine Biotechnology and Biomedicine, 9500 Gilman Drive \#0204, La Jolla, California 92093-0204; e-mail: gitte.mcdonald@gmail.com.
}

Physiological and Biochemical Zoology 85(3):243-254. 2012. (C) 2012 by The University of Chicago. All rights reserved. 1522-2152/2012/8503-1155\$15.00. DOI: $10.1086 / 665407$ sidering state variables in life-history studies and suggest that timing of measurements of effort in species with long provisioning periods may influence conclusions and our ability to make comparisons of reproductive effort among species.

\section{Introduction}

A central question in evolutionary ecology is how individuals optimize resource allocation. Life-history theory predicts that selection favors optimal levels of reproductive effort that balance the benefits of current reproduction with the costs to survival and future reproduction (Pianka and Parker 1975; Stearns 1992). At every stage in the reproductive cycle, parents should make decisions on how to allocate energy to their current offspring in order to increase the offspring's chance of survival while not jeopardizing their own future survival and reproduction (Williams 1966). However, on the basis of parentoffspring conflict theory, the optimal level of energy allocation that parents should supply to offspring may be less than the optimal level that offspring should demand (Trivers 1974). Therefore, the amount of energy allocated to offspring may depend on a variety of factors that balance the optimal levels of investment of the parent and offspring, including parental age, condition, experience, foraging ability, and offspring traits (Clutton-Brock 1984; Chastel et al. 1995; Clutton-Brock et al. 1996; Crocker et al. 2001). Although studies have investigated how these factors influence effort in a variety of species, relatively few have investigated concurrent effects of maternal traits, provisioning strategy, and offspring traits on reproductive energy allocation. Additionally, most have ignored how the importance of these factors may change across provisioning, although it is well known that provisioning effort is dynamic (Oftedal 1984; Oftedal et al. 1987a; Gill 1990).

In mammals, energy is provided to the offspring by the female and can be categorized as either prenatal or postnatal maternal care. For purposes of this study, prenatal maternal care is defined as the energy allocated to the fetus, while postnatal maternal care is the energy allocated to the offspring through lactation, which is the most energetically demanding component of reproduction (Gittleman and Oftedal 1987) and tends to be more difficult to measure. In most mammals studied, the amount of milk produced and the composition of the milk changes throughout lactation (Oftedal 1984; Oftedal et al. 1987a). Milk-energy output increases until peak lactation and declines before weaning (Oftedal 1984; Arnould et al. 1996). Peak lactation occurs days to weeks after parturition, depending 
on the lactation duration and species. This variability in milkenergy production may reflect dynamic influences on energy allocation to the offspring and fluctuations in the prey availability (Lea et al. 2002b, 2006).

Understanding how age influences energy allocation to offspring is central to many life-history studies of reproductive effort (Pianka and Parker 1975; Clutton-Brock 1984, 1991); however, many of these studies do not consider quality differences among conspecifics that might affect reproductive effort (Marrow et al. 1996; McNamara and Houston 1996). Age, size, and body condition are positively related to reproductive effort in many species (Clutton-Brock 1991; Chastel et al. 1995; Dobson and Michener 1995; Bowen et al. 2001). In northern elephant seals Mirounga angustirostris, there is a positive relationship between maternal age, size, and condition and reproductive effort. However, statistical analysis revealed that size and condition, and not age, were responsible for the increase in effort (Crocker et al. 2001), which highlighted the need to investigate how a variety of factors influence effort concurrently. One important factor that may affect the predicted relationship between maternal traits and reproductive effort is foraging behavior or pattern (Stearns 1992; Testa 2004). Animals that provision their offspring from distant food sources must balance the time needed to look for food before returning to their offspring with the time and energy provided to their offspring before returning to search for more food (Houston 1996; Costa 2008).

Maternal traits and provisioning strategy influence effort in many species, but other factors such as offspring traits may play an equally important role. The amount of energy that an offspring demands is often greater than the female's optimal level of supply. Early studies of parent-offspring conflict assumed or concluded that parents controlled energy allocation, but more recent studies suggest that offspring have a greater influence on demand than previously suspected (Gentry and Holt 1986; Royle et al. 2004). Factors such as offspring size may influence energy allocation because larger offspring will be able to consume and process more milk and may therefore have greater demand.

Capital breeders, animals that provision their offspring from energy reserves, are often the focus of maternal-care studies because effort can be determined from changes in body condition (Kovacs and Lavigne 1986; Iverson et al. 1993; Crocker et al. 2001). In capital breeders, size and condition are strongly correlated to reproductive effort and success (Festa-Bianchet et al. 1998; Côte and Festa-Bianchet 2001; Crocker et al. 2001); however, most mammals are income breeders, animals that provision offspring from current food intake. Although size and condition have been shown to be weakly correlated with reproductive effort in income breeders (Andersen et al. 2000; Boyd 2000), maternal traits, provisioning strategy, and offspring traits may have a different influence on energy allocation to offspring in income breeders (Costa 1993). For example, a study of European roe deer, an income breeder, found that maternal body weight did not have a pervasive effect on maternal care, contrary to authors' predictions (Andersen et al. 2000). In order to improve our understanding of how the above factors influence energy allocation to offspring in an income breeder, we investigated prenatal and postnatal maternal care in an otariid (sea lions and fur seals), the Antarctic fur seal Arctocephalus gazella Peters.

The Antarctic fur seal is an excellent system in which to examine these questions because these seals give birth to single young, thus removing complications due to litter size, and parental care is provided solely by the female through transfer of milk to her offspring. Additionally, weaning mass of pups is related to future survival and reproductive success, suggesting that increased maternal energy investment will increase the pups' fitness (Baker and Fowler 1992; Boltnev et al. 1998). Antarctic fur seals arrive at the colony after an 8-mo overwinter foraging trip. Within days of arrival, females give birth to a single pup and then stay with the pups for about 7-10 d (perinatal period). During this time, females must transfer enough milk to the pup so that it can survive a fast when the female departs on her first foraging trip to sea. After the perinatal period, females alternate short trips to the sea to feed (2-6 d) with short attendance visits to suckle their pups (1-2 d; Goebel et al. 2007; McDonald et al. 2009).

For this study we selected four stages of reproduction (prenatal, perinatal, pre-pup molt, and pup molt) to see how maternal traits, provisioning, and offspring traits influence energy allocation to the pup. During the perinatal study period, fur seals rely heavily on energy stores that they built up over the winter; therefore, maternal traits likely influence how much energy they transfer to the pup during this period. We selected for study the premolt $(1 \mathrm{mo})$ and molt $(2 \mathrm{mo})$ periods to represent stages when the mothers were alternating time spent feeding at sea with time spent ashore provisioning their pups. Two stages were selected because previous studies show that milk-energy output increases significantly during this time (Arnould et al. 1996). Our objectives were to (1) determine the relative importance of maternal traits, provisioning strategy, and offspring traits on the amount of energy allocated to offspring in an income breeder and (2) investigate how their importance may change across the period of investment.

\section{Material and Methods}

\section{Field Methods}

This study was conducted at Cape Shirreff, Livingston Island, Antarctica $\left(62^{\circ} 28^{\prime} \mathrm{S}, 60^{\circ} 46^{\prime} \mathrm{W}\right)$, during the austral summers of 2005-2006 and 2006-2007 (hereafter referred to as 2006 and 2007). Forty-nine known-age females from one of two age categories-young $(4-6 \mathrm{yr}, n=23)$ and prime $(8-14 \mathrm{yr}$, $n=26$ ) - and their pups were captured $1 \mathrm{~d}$ postpartum. Females were anesthetized with isoflurane gas with oxygen, using a portable field vaporizer setup (Gales and Mattlin 1998). Once anesthetized, females were measured and weighed $( \pm 0.2 \mathrm{~kg}$; Dynalink Systems International), milk samples were collected $(n=42)$, and VHF radio transmitters $(55 \mathrm{~mm} \times 22 \mathrm{~mm} \times$ $10 \mathrm{~mm}, 23 \mathrm{~g}$; Advanced Telemetry Systems, Isanti, MN) were attached to the fur with 5-min epoxy. Time-depth recorders 
were also attached to a subset of the females, for a concurrent study (McDonald et al. 2009). Additionally, some of the females were recaptured to collect milk samples approximately $5 \mathrm{~d}$ $(n=11), 1$ mo $(n=10)$, or 2 mo postpartum $(n=21)$.

Milk-consumption measurements were collected from the pups of captured females at three developmental stages-perinatal (newborn, $n=48$ ), premolt ( $1 \mathrm{mo}, n=45$ ), and molt ( 2 mo, $n=31$ ) —using the doubly labeled water (DLW) technique (Costa 1987b; Donohue et al. 2002). Sample size decreased with pup age because some pups were lost to predation (17 pups died because of suspected leopard seal predation; one pup died of starvation). Pups caught with their mothers were intubated with a 3/8-inch tube and milk was removed from the stomach, using a $120-\mathrm{mL}$ syringe (milk delays equilibrium and affects total body water [TBW] measurements; Oftedal et al. 1987b). Pups were weighed ( $\pm 0.10 \mathrm{~kg}$; Pescola spring scale), and a $10-\mathrm{mL}$ sample of blood for background measurements ("presample") was collected from the interdigital vein of the rear flipper. Pups were given an intraperitoneal injection of a weighed dose of 18-oxygen sterile saline $\left(\sim 2.0 \mathrm{~mL} / \mathrm{kg} 10 \%{ }^{18} \mathrm{O}\right.$; Cambridge Isotope Laboratories, Andover, MA) followed immediately by an intramuscular injection of a weighed dose of deuterated water in $2006\left(0.2 \mathrm{~mL} / \mathrm{kg} \mathrm{99.9 \%}{ }^{2} \mathrm{H}\right.$; Cambridge Isotope Laboratories) or tritiated water (HTO) in 2007 (1.5 $\mathrm{mL}$ of $7.5 \mathrm{MBq} / \mathrm{mL}^{3} \mathrm{H}$; American Radiolabeled Chemicals, St. Louis, MO). To ensure a complete equilibration of the isotopes, pups were held for $3 \mathrm{~h}$ and a 10 -mL blood sample was collected ("equilibrium sample") to determine TBW and initial ${ }^{18} \mathrm{O}$ and ${ }^{2} \mathrm{H}$ (or ${ }^{3} \mathrm{H}$ ) levels before they were returned to their mothers. Pups were recaptured 24-48 h after their mothers departed on their first trips to sea, to ensure that they were postabsorptive and had no milk in their stomachs. Once again pups were weighed, and a 10-mL blood sample was collected ("final sample") to determine water turnover during the study period, in order to calculate $\mathrm{CO}_{2}$ production.

Milk consumption was measured in the same pups at $1 \mathrm{mo}$ and 2 mo. Pups were weighed, and a background blood sample (presample) was collected (to correct for residual isotopes from previous sampling intervals in the TBW calculation) at least 24 $\mathrm{h}$ after the mothers departed to sea. Subsequently, pups were injected with DLW as described above, and $3 \mathrm{~h}$ later an equilibration blood sample was collected to determine TBW and initial ${ }^{18} \mathrm{O}$ and ${ }^{2} \mathrm{H}$ (or ${ }^{3} \mathrm{H}$ ) levels. One to $2 \mathrm{~d}$ after the female departed to sea following her attendance visit, the pup was recaptured and weighed and a final blood sample was collected. All blood samples were centrifuged shortly after collection, and serum samples were frozen at $-20^{\circ} \mathrm{C}$ for later analysis.

Foraging-trip duration and attendance of radio-tagged females was monitored by an automatic receiving station (VHF radio receiver, DCC II data logger, and omnidirectional antenna; Advanced Telemetry Systems). The station scanned each radio frequency for $30 \mathrm{~s}$ every $30 \mathrm{~min}$, allowing determination of foraging trip and attendance visit duration to within $1 \mathrm{~h}$ of actual duration. Any gap of $8 \mathrm{~h}$ or more that included nighttime hours was considered a foraging trip on the basis of previous studies using time-depth recorders to provide an independent measurement of attendance (U.S. Antarctic Marine Living Resources, unpublished data), and this was confirmed for females that carried time-depth recorders in this study (McDonald et al. 2009).

Animal use was performed under National Marine Fisheries Service permit 774-1649. All procedures were approved by the University of California, Santa Cruz, Animal Use Committee.

\section{Sample Analysis}

Pup serum samples were distilled in duplicate according to the method of Ortiz et al. (1978), and the ${ }^{3} \mathrm{H}$ activity of the samples was determined by counting $100 \mu \mathrm{L}$ of sample in $5 \mathrm{~mL}$ of scintillation cocktail with a Beckman model LS 3801 liquid scintillation counter. Specific activity of the HTO that was injected was determined at the same time from diluted samples of injectant. ${ }^{2} \mathrm{H}$ and ${ }^{18} \mathrm{O}$ enrichment levels of the 2006 samples were determined in duplicate by the University of California, Davis, Stable Isotope Facility, using a Los Gatos liquid water isotope analyzer, model DLT-100 (Los Gatos Research, Mountain View, CA), which uses technology based on high-resolution direct absorption spectroscopy. ${ }^{18} \mathrm{O}$ enrichment of the 2007 serum samples was determined by Metabolic Solutions (Nashua, NH), using gas isotope ratio mass spectrometry. Samples of injectant were sent to both labs to determine the enrichment of injectant. Five replicate enriched samples were sent to both labs for cross validation of results. There were no significant differences between the values obtained between labs (\% difference between the two labs: ${ }^{2} \mathrm{H}=3.2 \%,{ }^{18} \mathrm{O}=2.8 \%$ ).

\section{Body Condition, Field Metabolic Rate, and Milk-Intake Calculations}

TBW was determined from the dilution of ${ }^{18} \mathrm{O}$-labeled, water using the equation

$$
\mathrm{TBW}=
$$

enrichment of injectant $x$ injection volume

$\overline{\text { enrichment of equilibrium sample - enrichment of presample }}$.

For newborn pups, total body gross energy (TBGE) was calculated from TBW, using the equation derived empirically for Antarctic fur seal pups of similar age: TBGE (MJ) $=(31.7-$ 0.347 [TBW\%]) $\times$ pup birth mass (Arnould et al. 1996). Total water influx rates were calculated from the decrease in specific activity of ${ }^{3} \mathrm{H}\left(\right.$ or ${ }^{2} \mathrm{H}$ ) and equations (5) and (6) in Nagy and Costa (1980). $\mathrm{CO}_{2}$ production was calculated using a singlepool equation (Nagy and Costa 1980, eq. [3]), because singlepool equations are best for small animals and the Nagy equation allows for change in mass that is appropriate in growing pups (Speakman 1997). Daily energy expenditure was calculated from $\mathrm{CO}_{2}$ production, using a conversion factor of $27.44 \mathrm{~kJ} / \mathrm{L}$ $\mathrm{CO}_{2}$ (Costa 1987a) and assuming a respiration quotient of 0.7 for a milk-based diet (Schmidt-Nielsen 1979; Costa 1987a). Metabolic water production was calculated from the metabolic 
rate assuming a conversion factor of $0.0263 \mathrm{~g} \mathrm{H}_{2} \mathrm{O} / \mathrm{kJ}$ (SchmidtNielsen 1979).

Milk-consumption rates were calculated, using total water influx, metabolic water production values calculated for each individual pup, and the mean water and energy contents of milk sampled from study females during the perinatal period and 1 and 2 mo postpartum (McDonald 2009). Briefly, the water and energy contents of milk were measured in duplicate, using the oven-drying method and bomb calorimetry. There were no differences in water or energy content relative to year or maternal age, so the data for all animals were combined. Mean percentages (SD) of the water contents of milk for the perinatal $(n=42)$, premolt $(n=10)$, and molt $(n=21)$ periods that were used in calculations were $47.7 \%$ (4.9\%), 51.6\% (7.4\%), and $45.3 \%(6.2 \%)$, respectively, and mean (SD) energy content values were 17.74 (1.85), 15.82 (2.86), and 18.37 (2.30) $\mathrm{kJ} / \mathrm{g}$, respectively (McDonald 2009).

Milk intake was calculated for each pup, using the following equation:

$$
\begin{gathered}
\text { milk intake rate }= \\
\frac{\text { total water influx }- \text { metabolic water production }}{\text { milk water content } \%}
\end{gathered}
$$

(Ortiz et al. 1984; Costa 1987a). Milk intake was converted to energy consumed, using the energy content of milk that was determined for each study period. Water consumption has been shown to affect milk-intake calculations in Antarctic fur seals (Lea et al. 2002a); however, as it is rare to see pups drinking water at Cape Shirreff, we assumed that this was not a problem. Milk energy ingested per study period (total milk-energy intake per visit $[\mathrm{MJ}]$ ) was calculated as the milk-intake rate multiplied by the sampling interval (time between initial equilibrium sample and recapture sample), and it indicates the amount of energy that the female is allocating to her pup. Rate of milkenergy intake over the attendance visit was calculated by dividing total energy intake during the study period by the number of days the female was on land (milk-energy intake rate $[\mathrm{MJ} / \mathrm{d}])$. Additionally, for the 1- and 2-mo measurements, average daily milk consumption over the trip/visit cycle (daily milk intake over trip/visit cycle $[\mathrm{MJ} / \mathrm{d}]$ ) was calculated by dividing total energy transfer during a visit by trip/visit cycle duration, in order to evaluate the effect of trip duration on maternal energy allocation. The trip/visit cycle duration is the duration of the attendance visit during which measurements were collected plus the duration of the preceding foraging trip (trip/visit cycle $=$ trip duration [time at sea] + attendance duration [time on land]).

\section{Statistical Analysis}

The influence of maternal and pup traits and provisioning strategy on milk-energy intake in a visit (MJ), milk-energy intake rate during a visit $(\mathrm{MJ} / \mathrm{d})$, and average daily milk-energy intake rate over the trip/visit cycle (only the premolt and molt study periods) were investigated using linear mixed-effects models
(Cran R 2.12.2, package nlme). The independent variables in the model were maternal postpartum mass, maternal age class, pup sex, pup mass, pup age (perinatal, premolt, and molt), and study year. The model included two interaction terms, pup age $\times$ maternal mass and pup age $\times$ pup mass, to investigate whether the influences of maternal mass and pup mass changed across the study periods. In order to account for the lack of independence caused by repeatedly sampling the same animal over time, individual was included as a random effect. Covariance and random structures of the full models were evaluated using the corrected Akaike Information Criterion (AICc) and examination of residual plots. Once the covariance structure was selected, fixed-effects components were evaluated by comparing the models' AICc values. Effects were dropped if the simplified model had a lower AICc value, and residual plots were examined to assess model fit (Zuur et al. 2009).

General linear models (GLMs) were also used to investigate the influences of maternal and pup traits on prenatal and postnatal effort (Cran R 2.12.2, package stats). Because of the significance of the interaction term in the mixed-effects model, which indicates that the influences of maternal and pup traits on postnatal effort vary with pup age, separate GLMs for each postnatal study period were conducted to examine the influences of maternal and pup traits at different stages of the postnatal period. In all postnatal models, the independent variables were maternal postpartum mass, condition, age class (young/ prime), pup mass and sex, perinatal or trip/visit cycle duration, year, and two interaction terms (pup sex $\times$ maternal mass and pup sex $\times$ year). The dependent variable was either total milkenergy intake during a visit or average daily milk-energy intake over the perinatal study period or trip/visit cycle. Models were compared using AICc values, and effects were dropped if the simplified model had a lower AICc value when using a backward stepwise procedure (Zuur et al. 2007). Residual plots were examined to assess model fit. The condition index was calculated with the residuals from the regression of mass on body length (Trites 1991). Female mass and condition were represented by the postpartum values in all models, while pup mass at the start of the respective study period was used.

Data were tested for normality, homogeneity of variances, and multicollinearity before analysis, when necessary. Tolerances of the final model were also evaluated to check for multicollinearity, and they were $>0.4$ in all final models, indicating there was no correlation between independent variables. All means are expressed as mean \pm SD. Results were considered significant at the $P<0.05$ level.

\section{Results}

\section{Prenatal Effort}

Pup sex, maternal mass, and maternal condition influenced pup birth mass $\left(R^{2}=0.39, F_{3,45}=9.71, P<0.001\right)$; however, only maternal age was important when explaining the energy content of the pup at birth (table 1). Females that were heavier gave birth to heavier pups (table 1), and male pups were significantly heavier than female pups (tables 1,2). Although fe- 
Table 1: General linear model results identifying factors that influence the birth mass and pup total body gross energy (TBGE) content of Antarctic fur seals at Cape Shirreff, Livingston Island

\begin{tabular}{lcrrrr}
\hline Term & Coefficient (SE) & \multicolumn{1}{c}{$t$} & $P$ & $\eta^{2}$ & $95 \%$ CI \\
\hline Birth mass, kg: & & & & & \\
$\quad$ Pup sex (male $>$ female) & $-.67(.17)$ & -3.84 & $<.001$ & .25 & $.06-.42$ \\
$\quad$ Maternal mass & $.044(.012)$ & 3.52 & .001 & .22 & $.04-.39$ \\
$\quad$ Maternal condition & $.060(.023)$ & 2.57 & .014 & .13 & $.00-.30$ \\
Pup TBGE content, MJ: & & & & & \\
$\quad$ Maternal age class (prime $>$ young) & $6,995(2,524)$ & 2.77 & .008 & .14 & $.01-.32$ \\
\hline
\end{tabular}

Note. Full models included pup sex, maternal mass, condition, and age class. Only the best models are presented. CI $=$ confidence interval.

${ }^{\mathrm{a}} n=49,39.3 \%$ of variance explained.

${ }^{\mathrm{b}} n=49,14.0 \%$ of variance explained.

males in better condition also gave birth to larger pups, the effect was very small (table 1). When the energy content of the pups was examined, prime-age females were allocating significantly more energy to their pups (prime: $45.7 \pm 9.9$ TJ; young: $38.7 \pm 7.4 \mathrm{TJ}, t=2.77, P=0.008)$; however, maternal age explained only $14 \%$ of the variation in pups' energy content at birth. Pup sex was not significantly related to energy content at birth, indicating that females were investing equal amounts of energy in male and female pups.

\section{Postnatal Effort}

The amount of milk energy consumed during a bout, the rate at which milk energy was consumed during a bout, and the average daily milk-energy intake over a trip/cycle changed significantly during the first 2 mo of lactation (tables 2, 3). The greatest amount of milk consumed during a bout was during the perinatal period and at $2 \mathrm{mo}$, but the rate of consumption was significantly higher at 2 mo (table 2; fig. 1). Maternal mass and pup age (perinatal, premolt, molt) and the interaction between the two influenced milk-energy intake during a bout (table 3). Pup mass and the interaction of pup age with both pup and maternal mass influenced average daily milk intake over the trip/visit cycle. The significant interaction terms indicate that the effects of maternal mass and pup mass on milkenergy intake during a bout and over the trip/visit cycle are dynamic and change with pup age, so GLMs were also conducted to look at each postnatal study period separately. Maternal mass, pup mass, and pup age also influenced milk-energy intake rate, with heavier, older pups from heavier females ingesting milk at a faster rate (table 3; fig. 1). Including individual as a random effect did not improve the mixed-effects model (milk-energy intake in bout - likelihood ratio $=0.14, P=$ 0.71 ; milk-energy intake rate - likelihood ratio $<0.001, P=$ 1.0; average daily milk-energy intake over trip/visit cycle likelihood ratio $=0.25, P=0.62$ ), but it was included in all the mixed-effects models to account for repeated measures.

The relative importance of maternal traits, pup traits, and provisioning strategy on milk intake varied across the study periods as indicated by the significant interaction term in the mixed-effects models. During the perinatal period, only ma- ternal traits (mass, condition, and age class) and provisioning strategy (perinatal duration) influenced milk intake (table 4). Pups of heavier and better-condition females who experienced a longer perinatal period consumed more milk energy (table 4), while pups of older females (when controlled for mass and condition) consumed less energy during the perinatal period; however, maternal mass and duration of the perinatal period had the greatest effect and explained most of the variation (table 4). When examining the influences of maternal and pup traits on milk-intake rate $(\mathrm{MJ} / \mathrm{d})$, only maternal mass and perinatal duration were important. Larger females provided milk to their offspring at a faster rate, while females with longer perinatal durations provided milk at a lower daily rate (table 4). Pup sex and pup birth mass did not influence total milk intake or intake rate.

At $1 \mathrm{mo}$, maternal traits were no longer important and only pup mass and cycle duration were significant predictors of milk-energy consumption during the attendance visit $(n=$ $45, R^{2}=0.61, F_{2,42}=32.34, P<0.001$, pup mass $\eta^{2}=0.30$, trip/visit cycle $\eta^{2}=0.58$ ). Only pup mass was significant when predicting the average daily rate of milk-energy consumption over the trip/visit cycle $\left(R^{2}=0.25, F_{1,43}=14.33, P<0.001\right.$; fig. $2 a$ ). Females that have longer trip/visit cycles (i.e., longer trip and visit) transfer more energy to their pups in an attendance visit; however, when intake is divided by the cycle duration, there is no difference in intake rate. Larger pups had a greater average daily milk intake over the trip/visit cycle (fig. $2 a$ ).

By 2 mo, maternal mass again became important and pup traits were no longer significant. Maternal mass and cycle duration were significant predictors of total milk-energy consumption during the attendance visit $\left(n=31, R^{2}=0.71\right.$, $F_{2,28}=33.57, P<0.001$, maternal mass $\eta^{2}=0.45$, trip/visit cycle $\eta^{2}=0.69$ ), but only maternal mass was significantly related to the average daily rate of milk-energy consumption over the trip/visit cycle, with pups of larger females ingesting more milk $\left(R^{2}=0.42, F_{1,29}=21.10, P<0.001\right.$; fig. $\left.2 b\right)$.

\section{Discussion}

Maternal traits, pup traits, and provisioning influenced energy allocated to pups, but the relative importance of these factors 


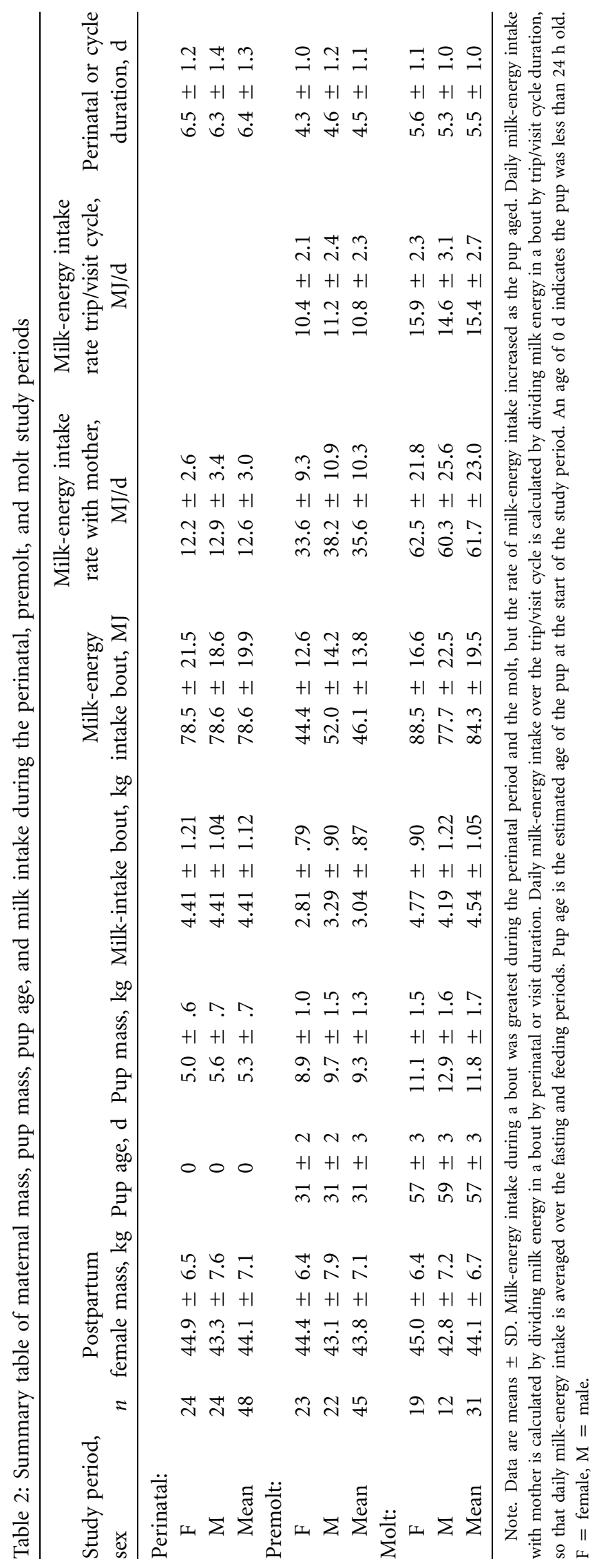


Table 3: Mixed-effect model results investigating the relationship between maternal and pup traits on milk-energy intake during a nursing bout, milk-energy intake rate over a nursing bout, and average daily milk-energy intake over a foraging-trip/visit cycle

\begin{tabular}{lrrr}
\hline Term & Coefficient (SE) & \multicolumn{1}{c}{$t$} & $P$ \\
\hline Milk-energy intake/visit, MJ: ${ }^{\mathrm{a}}$ & & & \\
$\quad$ Pup age class: & & & \\
$\quad$ Premolt & $40.71(19.13)$ & 2.13 & .037 \\
$\quad$ Molt & $58.94(27.40)$ & 2.15 & .035 \\
Maternal mass & $1.66(.35)$ & 4.73 & $<.001$ \\
Premolt pup age class $\times$ maternal mass & $-1.63(.44)$ & -3.71 & $<.001$ \\
Molt pup age class $\times$ maternal mass & $-1.18(.63)$ & -1.88 & .064 \\
Milk-energy intake rate with mother, MJ/d: ${ }^{\mathrm{a}}$ & & & \\
Pup age class: & & & \\
$\quad$ Premolt & $19.24(2.27)$ & 7.49 & $<.001$ \\
$\quad$ Molt & $42.15(5.23)$ & 8.07 & $<.001$ \\
Maternal mass & $.17(.06)$ & 2.90 & .005 \\
Pup mass & $1.07(.51)$ & 2.11 & .039 \\
Average milk-energy intake rate cycle, MJ/d: ${ }^{\mathrm{b}}$ & & & \\
Pup age class & $3.10(3.66)$ & .85 & .406 \\
Maternal mass & $.002(.05)$ & .05 & .962 \\
Pup mass & $.85(.27)$ & 3.19 & .004 \\
Pup age class $\times$ maternal mass & $.29(.08)$ & 3.62 & .001 \\
Pup age class $\times$ pup mass & $-1.15(.37)$ & -3.16 & .004 \\
\hline
\end{tabular}

Note. The significant interaction terms in two of the models indicates that the influences of maternal and pup traits change across lactation. The full model included the following independent variables: maternal mass, maternal age class, pup sex, pup mass and pup age (perinatal, premolt, and molt), study year, and the interaction terms pup age $\times$ maternal mass and pup age $\times$ pup mass. Only the best models are presented.

${ }^{a} n=122$, individuals $=47$.

${ }^{\mathrm{b}} n=76$, individuals $=45$.

changed across the investment period. Maternal traits were important during three of the four stages we investigated, with larger females giving birth to larger pups and allocating more energy to their pups during the perinatal and molt study periods. Pup mass influenced only maternal care during the premolt study period. Previous studies of Antarctic fur seals have provided conflicting results on how maternal traits influence maternal care. For example, one study found that older females weaned heavier pups but there was no influence of maternal mass or condition (Doidge and Croxall 1989), another study found no relationship between pup mass and growth and maternal traits (Lunn et al. 1993), and a third study found that longer females had heavier pups (Guinet et al. 2000). Three explanations for the lack of consistency are that (1) all of these studies used one measurement during the investment period to address the influence of maternal traits and were not able to assess changes across lactation, (2) they used proxies for investment (mass or growth rate) that can be influenced by other factors such as pup activity levels and weather rather than milk-energy investment, and (3) annual differences in food availability may influence energy allocation strategy.

Maternal traits influenced maternal care, with maternal mass being the most important factor, as has been found in many mammals (Crocker et al. 2001; Broussard et al. 2005; Landete-
Castillejos et al. 2009). Maternal mass influenced pup birth mass, with heavier females giving birth to larger pups. The influence of maternal mass on pup birth mass was reported previously in Antarctic fur seals and other mammals (Costa et al. 1988; Descamps et al. 2007; Landete-Castillejos et al. 2009). Despite the influence of maternal mass on pup mass, maternal mass or condition were not significant drivers of pup energy content. Only maternal age affected pup energy content at birth, but it only explained a small amount of variation (14\%).

The influence of maternal mass on maternal care was variable during the postnatal investment period. Maternal mass influenced energy allocation to the pup in two of the three study periods (perinatal and molt). During the perinatal period, when otariids rely on stored body reserves accumulated over the winter, mass was positively related to the amount of energy allocated to the pup. Maternal mass did not influence the amount of energy allocated to the pup during the premolt study period, but at 2 mo female mass was again positively related to milkenergy intake and milk-intake rate (fig. 2). At this stage, the rate of milk transfer was the highest measured in this study. Pups ingested similar or greater amounts of milk energy in a short 2-d visit as they did during the entire perinatal period (78.6 \pm 19.9 and $84.3 \pm 19.5 \mathrm{MJ}$, respectively; table 2$)$. At these high levels of energy transfer, the amount of energy the female 


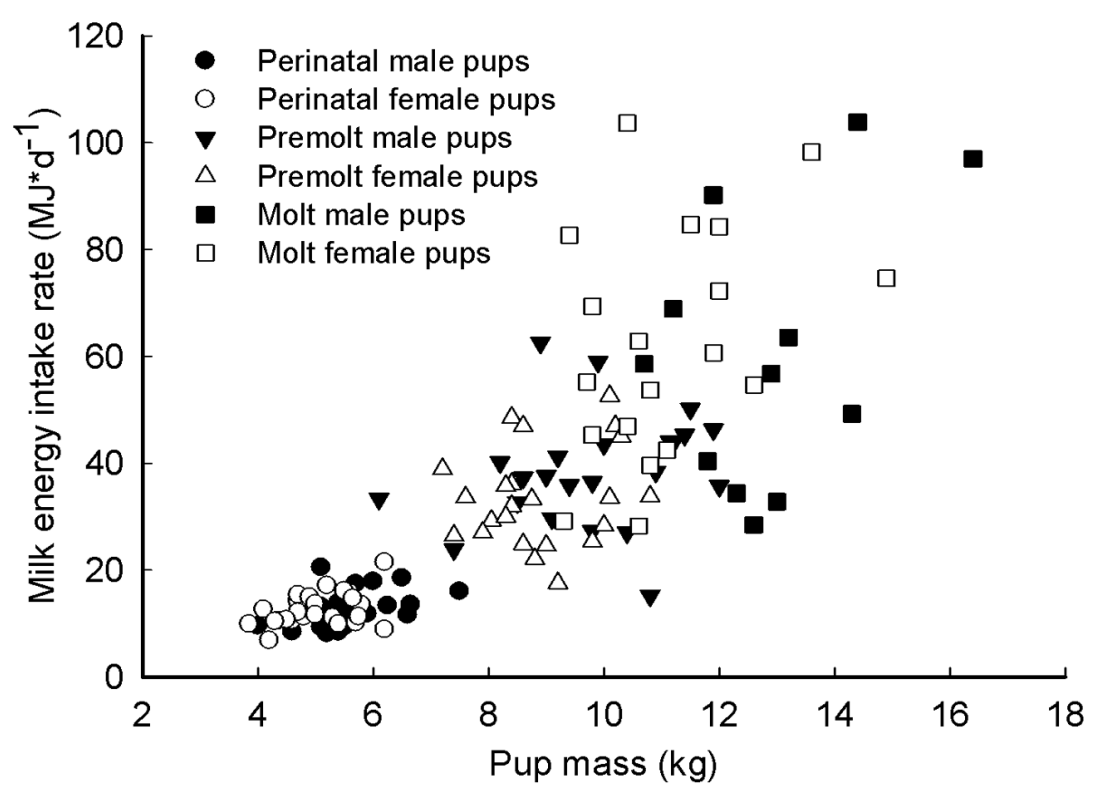

Figure 1. Milk-energy intake rate of Antarctic fur seal pups as a function of pup mass for the three study periods (circles $=$ perinatal, $n=$ 48; triangles $=$ premolt, $n=45$; squares $=$ molt, $n=31$; unfilled symbols $=$ female pups, filled symbols $=$ male pups). Milk-energy intake rate increases with increasing pup mass $(t=2.03, P=0.047)$ and age $(t=8.95, P<0.001)$ in Antarctic fur seals (table 3$)$.

provided to her pup while fasting might have been limited by female size and energy stores (Beauplet and Guinet 2007). At a breeding colony in the Kerguelen Archipelago, longer Antarctic fur seal females weaned larger pups, but only in years of low food availability (Lea et al. 2006). Trip duration and pup growth rate indicate that food availability was good for both years of this study (McDonald et al. 2009). In a year with poor foraging conditions, maternal traits may have an even greater influence on maternal care than we measured in this study.

Pup mass also influenced maternal care, but only during the premolt study period, when maternal mass was not important. At $1 \mathrm{mo}$, the amount and rate of milk energy consumed increased significantly with pup mass, which is consistent with comparable studies in otariids (Costa and Gentry 1986; Arnould et al. 1996; Arnould and Hindell 2002). This suggests that pup demand has an influence on postnatal maternal care. The slow rate of energy transfer during the perinatal period is likely influenced by the small size of the pups. Despite this, there is no relationship between milk-energy intake rate and pup size at this age, and the total amount transferred and the rate at which it is transferred is determined primarily by maternal size. During the premolt period, the relationship between pup mass and milk-energy intake over the attendance visit (and daily milk-energy intake rate over the trip/visit cycle) suggests that during the early stage of lactation, milk-energy ingestion is likely limited by pup size. Pups may be able to assimilate more milk if it was spread over a longer period, but at this age they ingested more than $2 \mathrm{~kg}$ in a short 1-2-d period, and this may decrease their appetite (Arnould et al. 2001). Larger pups will be able to consume and process more milk and therefore be able to demand more milk energy from their mothers. At
2 mo, pups were larger and consumed significantly more milk during a visit and at a faster rate than they did at $1 \mathrm{mo}$, but milk consumption was no longer related to pup mass. At some point between 1 and 2 mo, pup size was no longer limiting, and female mass became important again. This is consistent with Arnould et al.'s (2001) study in similarly aged Antarctic fur seal pups, which found that pups could assimilate more milk than they obtained from their mothers and concluded that maternal investment patterns are not limited by offspring demand in older pups. A similar pattern was seen in subAntarctic fur seals (Arctocephalus tropicalis Gray), where young pups controlled maternal care, but by approximately 4 mo, maternal traits became more important (Georges and Guinet 2000). In Antarctic fur seals, whose lactation period is less than half that of sub-Antarctic fur seals, it appears that maternal traits become important again much sooner.

Pup sex did not influence maternal care. Previous studies investigated differential investment in Antarctic fur seals and found that although male pups tended to be larger (Costa et al. 1988; Lunn et al. 1993; Arnould et al. 1996), there was little evidence that females invested more in male pups, consistent with this study (Arnould et al. 1996; Lunn and Arnould 1997). Mothers allocated the same amount of energy in male and female pups in utero, but how they allocated the energy to lean tissue or fat was different. As large size is important for males later in life, putting the energy toward structural growth may be important (Arnould et al. 2001). Although pup sex did not influence postnatal investment directly-because male pups were significantly larger than female pups and mothers invested more in larger pups during the premolt study period-females invested more in male pups (table 2). A benefit to giving birth 
Table 4: General linear model results identifying factors that influence total perinatal milk-energy intake and perinatal milk-energy intake rate of Antarctic fur seal pups at Cape Shirreff, Livingston Island

\begin{tabular}{|c|c|c|c|c|c|}
\hline Term & Coefficient (SE) & $t$ & $P$ & $\eta^{2}$ & $95 \% \mathrm{CI}$ \\
\hline \multicolumn{6}{|c|}{ Perinatal milk-energy intake/bout, MJ: ${ }^{a}$} \\
\hline Maternal mass, $\mathrm{kg}$ & $2.31(.46)$ & 5.07 & $<.001$ & .37 & $.14-.52$ \\
\hline Maternal condition & $1.22(.60)$ & 2.02 & .049 & .09 & $.00-.25$ \\
\hline Age class (prime $>$ young ) & $-15.08(6.59)$ & -2.29 & .027 & .08 & $.00-.28$ \\
\hline Perinatal duration, $\mathrm{d}$ & $6.84(1.66)$ & 4.12 & $<.001$ & .28 & $.07-.45$ \\
\hline \multicolumn{6}{|c|}{ Milk-energy intake rate with mom, MJ/d: ${ }^{\mathrm{b}}$} \\
\hline Maternal mass, $\mathrm{kg}$ & $.23(.05)$ & 4.77 & $<.001$ & .34 & $.12-.50$ \\
\hline Perinatal duration, $\mathrm{d}$ & $-.96(.27)$ & -3.59 & $<.001$ & .22 & $.04-.40$ \\
\hline
\end{tabular}

Note. Full models included the following independent variables: maternal mass, maternal condition, maternal age class, perinatal duration, pup sex, pup mass and the interaction terms pup sex $\times$ maternal mass and pup sex $\times$ year, and independent variables. Only the best models are presented. $\mathrm{CI}=$ confidence interval.

${ }^{\mathrm{a}} n=48,54.7 \%$ of variance explained.

${ }^{\mathrm{b}} n=48,41.9 \%$ of variance explained.

to heavier male pups is that there is a positive correlation between pup mass at birth and at 1 and 2 mo (fig. 3 ). Therefore, heavier male pups at birth may have long-lasting benefits because from some period between the perinatal and molt study periods, females are investing more in larger male pups. These results are consistent with other studies investigating differential investment in otariids (Arnould et al. 1996; Arnould and Hindell 2002; Donohue et al. 2002).

In addition to the influences of maternal and pup mass on maternal care, maternal provisioning strategy influenced the amount of energy allocated to pups, especially during the peri- natal period. During the perinatal period, the amount of energy allocated was related to perinatal duration. Females with longer perinatal periods invested significantly more energy in their offspring even though they transferred energy at a slower rate, which would result in a greater metabolic overhead (amount of total energy expenditure that goes to meeting the females' metabolic demands). These data suggest that an ideal strategy to increase efficiency is to transfer energy at a faster rate so that females could spend less time on land (Costa 1993; McDonald and Crocker 2006). This would allow more total energy expenditure during the perinatal period to go to the
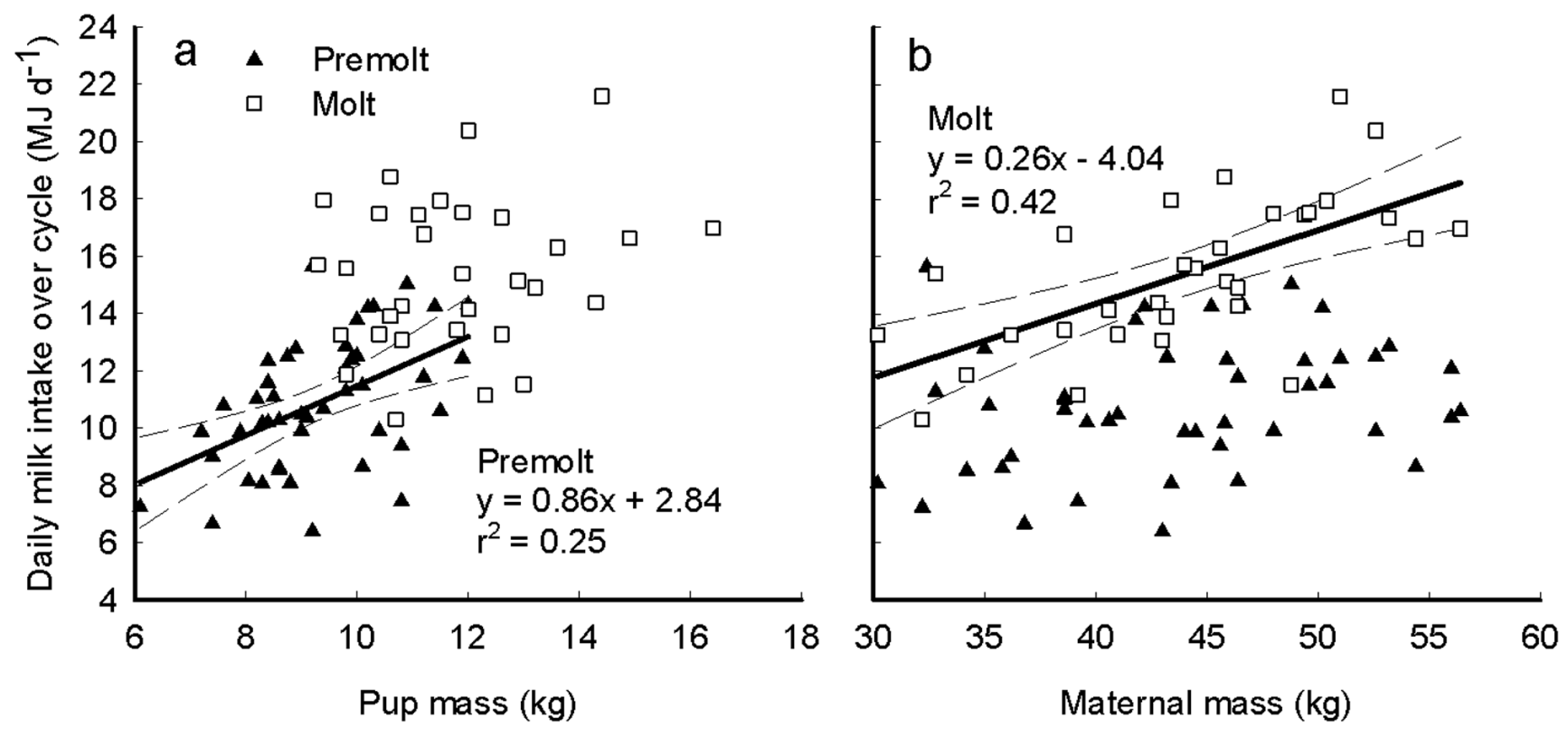

Figure 2. Daily milk-energy intake over the trip/visit cycle as a function of pup mass $(a)$ and maternal mass $(b)$ for Antarctic fur seal pups at Cape Shirreff, Antarctica, during the premolt (filled triangles; $n=45$ ) and molt (unfilled squares; $n=31$ ) study periods. Pup mass was related to daily milk-energy intake only during the premolt study period $\left(F_{1,43}=14.33, P<0.001\right)$. Maternal mass was significantly related to daily milk-energy intake only during the molt study period $\left(F_{1,29}=21.10, P<0.001\right)$. Dashed lines indicate $95 \%$ confidence intervals. 


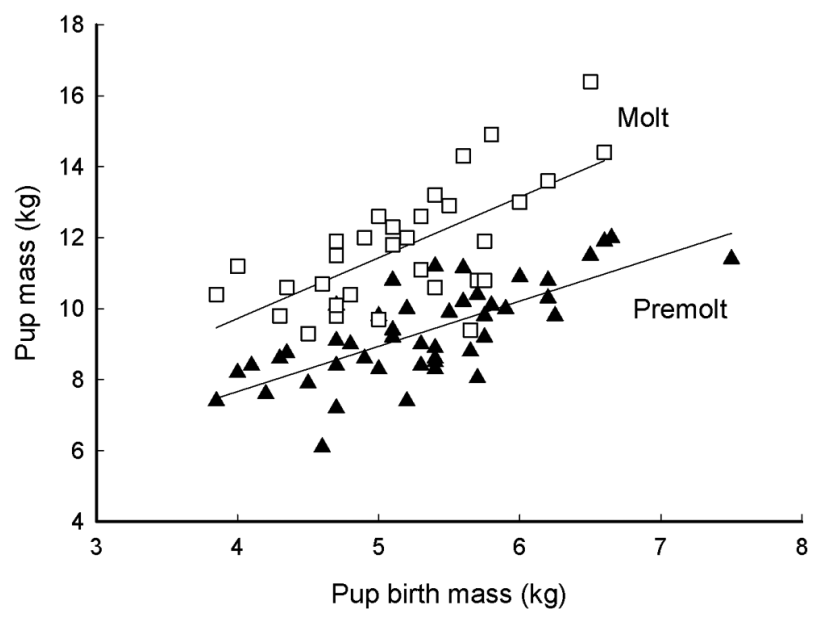

Figure 3. Pup mass during the premolt (filled triangles) and molt (unfilled squares) study periods. Pup mass during these periods is significantly correlated to pup birth mass in Antarctic fur seal pups (premolt: Pearson's $r=0.72, P<0.001, n=45$; molt: Pearson's $r=0.67, P<0.001, n=31)$.

pup rather than maintenance. However, there may be a tradeoff between an optimization of energy transfer and providing protection to the pup when the pup is very young and/or a trade-off in pups between the ability to digest milk rapidly and the energetic cost of maintaining a large reproductive tract.

The trip/visit cycle duration significantly affected how much energy females transferred to their pups during an attendance visit, as is expected for an income breeder, which depends on food obtained during lactation to provision their offspring. Females with longer foraging-trip/visit cycles transferred more energy to their pups during an attendance visit, but when the energy the pup obtained during an attendance visit was averaged over the trip/visit cycle, there was no relationship to cycle duration, indicating that the females were optimizing energy transfer and suggesting that one trip length was not better than another in the range of trip durations we observed. In sub-Antarctic fur seals there was also a "window" of trip durations where the rate of food delivery did not vary with trip duration, but once trip duration exceeded this window, the rate of food delivery decreased (Georges and Guinet 2000). In the $2 \mathrm{yr}$ of this study, all females made relatively short and regular trips (McDonald et al. 2009), which might explain why there was no relationship between trip/visit cycle duration and average milk energy consumed. Although average daily milk-energy transfer may not differ between the range of trip/visit cycle durations we measured, it is possible that how pups invest obtained energy toward growth and maintenance varies with trip/visit cycle length (Verrier et al. 2009).

This study contributes to our knowledge about how individual Antarctic fur seals allocate energy toward reproduction. Maternal mass, pup mass, and provisioning strategy are important in determining maternal care. Although we found little evidence that maternal age influences maternal care, this could be a result of the study design. This was a cross-sectional study, and it is possible that if we followed individuals over their life spans we might see more subtle changes in maternal care with increasing age. Another potential weakness of this study is that because of logistical constraints, we used mean milk water and energy content values that were averaged from all milk samples collected during the respective study periods. Individual females may differ in the composition of their milk because of their physiological capacity to produce milk and/or because of dietary differences, and this might affect some of the results in the study (Lea et al. 2006; McDonald and Crocker 2006; Lang et al. 2009).

Many factors, including the ability of females to acquire energy, their ability to transform that energy into milk, and the offspring's ability to ingest the milk, ultimately affect the magnitude of maternal care. We conclude that although income breeders feed during the investment period, maternal traits, especially size, influence maternal care as they do in many organisms (Pomeroy et al. 1999; Andersen et al. 2000; Crocker et al. 2001; Broussard et al. 2005). This is consistent with studies in other mammalian income breeders (Colombian squirrel and European roe deer) that found a correlation between parturition mass and/or condition with offspring growth (Andersen et al. 2000; Broussard et al. 2005). Even in animals that rely primarily on energetic income during the reproductive period, initial capital is important in determining the amount of energy allocated to offspring (Broussard et al. 2005). In income breeders, large size may provide a benefit because larger animals will be able to store more fat than smaller animals when food is abundant, and they can rely on this fat when offspring demand starts to exceed energy intake or food is temporarily unavailable (Beauplet and Guinet 2007). Additionally, we show that the relative importance of maternal mass, offspring mass, and provisioning are dynamic across the investment period, suggesting that offspring demand is important in influencing maternal care and during some periods it is more important than maternal mass. These findings stress the importance of state variables in life-history studies and suggest that timing of measurements of investment in species with long provisioning periods may influence conclusions and the ability to make comparisons of reproductive effort among species.

\section{Acknowledgments}

We thank all those who assisted with the collection of the data, in particular C. Champagne, R. Haner, and S. Seganti. Logistical support was provided by the U.S. Antarctic Marine Living Resources (AMLR) Program, the National Science Foundation (NSF) U.S. Antarctic Program, and Raytheon Polar Services. This article was improved by comments from two anonymous reviewers. Research was funded by the U.S. AMLR Program and NSF Office of Polar Programs grant 0440687 to D.P.C, D.E.C., and M.E.G. B.I.M. was supported by the U.S. Environmental Protection Agency (EPA) under the Science to Achieve Results Graduate Fellowship Program and an NSF graduate fellowship. The EPA has not officially endorsed this publication, and the views expressed herein may not reflect the views of the EPA. 


\section{Literature Cited}

Andersen R., J.-M. Gaillard, J.D.C. Linnell, and P. Duncan. 2000. Factors affecting maternal care in an income breeder, the European roe deer. J Anim Ecol 69:672-682.

Arnould J.P.Y., I.L. Boyd, D.R. Rawlins, and M.A. Hindell. 2001. Variation in maternal provisioning by lactating Antarctic fur seals (Arctocephalus gazella): response to experimental manipulation in pup demand. Behav Ecol Sociobiol 50:461-466.

Arnould J.P.Y., I.L. Boyd, and D.G. Socha. 1996. Milk consumption and growth efficiency in Antarctic fur seal (Arctocephalus gazella) pups. Can J Zool 74:254-266.

Arnould J.P.Y. and M.A. Hindell. 2002. Milk consumption, body composition and pre-weaning growth rates of Australian fur seal (Arctocephalus pusillus doriferus) pups. J Zool (Lond) 256:351-359.

Baker J.D. and C.W. Fowler. 1992. Pup weight and survival of northern fur seals Callorhinus ursinsus. J Zool (Lond) 227: 231-238.

Beauplet G. and C. Guinet. 2007. Phenotypic determinants of individual fitness in female fur seals: larger is better. Proc $\mathrm{R}$ Soc B 274:1877-1883.

Boltnev A.I., A.E. York, and G.A. Antonelis. 1998. Northern fur seal young: interrelationships among birth size, growth, and survival. Can J Zool 76:843-854.

Bowen W.D., S.J. Iverson, D.J. Boness, and O.T. Oftedal. 2001. Foraging effort, food intake and lactation performance depend on maternal mass in a small phocid seal. Funct Ecol 15:325-334.

Boyd I.L. 2000. State-dependent fertility in pinnipeds: contrasting capital and income breeders. Funct Ecol 14:623-630.

Broussard D.R., F.S. Dobson, and J.O. Murie. 2005. The effects of capital on an income breeder: evidence from female Colombian ground squirrels. Can J Zool 83:546-552.

Chastel O., H. Weimerskirch, and P. Jouventin. 1995. Influence of body condition on reproductive decision and reproductive success in the blue petrel. Auk 112:964-972.

Clutton-Brock T.H. 1984. Reproductive effort and terminal investment in iteroparous animals. Am Nat 123:212-229.

- 1991. The evolution of parental care. Princeton University Press, Princeton, NJ.

Clutton-Brock T.H., I.R. Stevenson, P. Marrow, A.D. MacColl, A.I. Houston, and J.M. McNamara. 1996. Population fluctuations, reproductive costs, and life-history tactics in female Soay sheep. J Anim Ecol 65:675-689.

Costa D.P. 1987a. Isotopic methods for quantifying material and energy intake of free-ranging marine mammals. Pp. 4366 in A.C. Huntley, ed. Approaches to marine mammal energetics. Allen, Lawrence, KS.

- 1987b. Methods for studying the energetics of freely diving animals. Can J Zool 66:45-52.

. 1993. The relationship between reproductive and foraging energetics and the evolution of the Pinnipedia. Pp. 293-314 in I.L. Boyd, ed. Marine mammals: advances in behavioural and population biology. Oxford University Press, Oxford.
2008. A conceptual model of the variation in parental attendance in response to environmental fluctuation: foraging energetics of lactating sea lions and fur seals. Aquat Conserv 17:S44-S52.

Costa D.P. and R.L. Gentry. 1986. Free-ranging energetics of northern fur seals. Pp. 79-101 in R.L. Gentry and G.L. Kooyman, eds. Fur seals: maternal strategies on land and at sea. Princeton University Press, Princeton, NJ.

Costa D.P., F. Trillmich, and J.P. Croxall. 1988. Intraspecific allometry of neonatal size in the Antarctic fur seal. Behav Ecol Sociobiol 22:361-364.

Côte S.D. and M. Festa-Bianchet. 2001. Birthdate, mass and survival in mountain goat kids: effects of maternal characteristics and forage quality. Oecologia 127:230-238.

Crocker D.E., J.D. Williams, D.R. Costa, and B.J. Le Boeuf. 2001. Maternal traits and reproductive effort in northern elephant seals. Ecology 82:3541-3555.

Descamps S., S. Boutin, D. Berteaux, and J.-M. Gaillard. 2007. Female red squirrels fit Williams' hypothesis of increasing reproductive effort with increasing age. J Anim Ecol 76:11921201.

Dobson F.S. and G.R. Michener. 1995. Maternal traits and reproduction in Richardson's ground squirrels. Ecology 76: 851-862.

Doidge D.W. and J.P. Croxall. 1989. Factors affecting weaning weight in Antarctic fur seals Arctocephalus gazella at South Georgia. Polar Biol 9:155-160.

Donohue M.J., D.P. Costa, E. Goebel, G.A. Antonelis, and J.D. Baker. 2002. Milk intake and energy expenditure of freeranging northern fur seal, Callorhinus ursinus, pups. Physiol Biochem Zool 75:3-18.

Festa-Bianchet M., J.M. Gaillard, and J.T. Jorgensen. 1998. Mass- and density-dependent reproductive success and reproductive costs in a capital breeder. Am Nat 152:367-379.

Gales N.J. and R.H. Mattlin. 1998. Fast, safe, field-portable gas anesthesia for otariids. Mar Mamm Sci 14:355-361.

Gentry R.L. and J.R. Holt. 1986. Attendance behavior of northern fur seals. Pp. 41-60 in R.L. Gentry and G.L. Kooyman, eds. Fur seals: maternal strategies on land and at sea. Princeton University Press, Princeton, NJ.

Georges J.-Y. and C. Guinet. 2000. Maternal care in the subAntarctic fur seals on Amsterdam Island. Ecology 81:295-308. Gill P.F. 1990. Ornithology. W.H. Freeman, New York.

Gittleman J.L. and O.T. Oftedal. 1987. Comparative growth and lactation energetics in carnivores. Pp. 41-77 in A. Loudon and P.A. Racey, eds. Reproductive energetics in mammals. Oxford University Press, Oxford.

Goebel M.E., B.I. McDonald, R. Haner, C. Champagne, J.D. Lipsky, and R.S. Holt. 2007. Pinniped research at Cape Shirreff. Pp. 122-143 in J.D. Lipsky, ed. AMLR 2006/2007 Field Season Report. NOAA-TM-NMFS-SWFSC-409. National Oceanic and Atmospheric Administration, La Jolla, CA.

Guinet C., M.-A. Lea, and S.D. Goldsworthy. 2000. Mass change in Antarctic fur seal (Arctocephalus gazella) pups in relation to maternal characteristics at the Kerguelen Islands. Can J Zool 78:476-483. 
Houston A.I. 1996. The use of a time and energy budget model of a parent bird to investigate limits to fledging mass in the thick-billed murre. Funct Ecol 10:432-439.

Iverson S.J., W.D. Bowen, D.J. Boness, and O.T. Oftedal. 1993. The effect of maternal size and milk energy output on pup growth in grey seals (Halichoerus grypus). Physiol Zool 66: 61-88.

Kovacs K.M. and D.M. Lavigne. 1986. Maternal investment and neonatal growth in phocid seals. J Anim Ecol 55:1035-1051.

Landete-Castillejos T., A. García, D. Carrión, J.A. Estevez, F. Ceacero, E. Gaspar-López, and L. Gallego. 2009. Age-related body weight constraints on prenatal and milk provisioning in Iberian red deer (Cervus elaphus hispanicus) affect allocation of maternal resources. Theriogenology 71:400-407.

Lang S.L.C., S.J. Iverson, and W.D. Bowen. 2009. Repeatability in lactation performance and the consequences for maternal reproductive success in gray seals. Ecology 90:2513-2523.

Lea M.-A., F. Bonadonna, M.A. Hindell, C. Guinet, and S.G. Goldsworthy. 2002a. Drinking behaviour and water turnover rates of Antarctic fur seal pups: implications for the estimation of milk intake by isotopic dilution. Comp Biochem Physiol 132:321-331.

Lea M.-A., Y. Cherel, C. Guinet, and P.D. Nichols. 2002b. Antarctic fur seals foraging in the polar frontal zone: inter-annual shifts in diet as shown from fecal and fatty acid analyses. Mar Ecol Prog Ser 245:281-297.

Lea M.-A., C. Guinet, Y. Cherel, G. Duhamel, L. Dubroca, P. Pruvost, and M.A. Hindell. 2006. Impacts of climatic anomalies on provisioning strategies of a Southern Ocean predator. Mar Ecol Prog Ser 310:77-94.

Lunn N.J. and J.P.Y. Arnould. 1997. Maternal investment in Antarctic fur seals: evidence for equality in the sexes? Behav Ecol Sociobiol 40:351-362.

Lunn N.J., I.L. Boyd, T. Barton, and J.P. Croxall. 1993. Factors affecting the growth rate and mass at weaning of Antarctic fur seals at Bird Island, South Georgia. J Mammal 74:908-919.

Marrow P., J.M. McNamara, A.I. Houston, I.R. Stevenson, and T.H. Clutton-Brock. 1996. State-dependent life history evolution in Soay sheep: dynamic modelling of reproductive scheduling. Philos Trans R Soc B 351:17-32.

McDonald B.I. 2009. The reproductive energetics of Antarctic fur seals (Arctocephalus gazella): influence of maternal traits and foraging behavior on maternal investment. $\mathrm{PhD}$ diss. University of California, Santa Cruz.

McDonald B.I. and D.E. Crocker. 2006. Physiology and behavior influence lactation efficiency in northern elephant seals (Mirounga angustirostris). Physiol Biochem Zool 79: 484-496.

McDonald B.I., M.E. Goebel, D.E. Crocker, Y. Tremblay, and D.P. Costa. 2009. Effects of maternal traits and individual behavior on the foraging strategies and provisioning rates of an income breeder, the Antarctic fur seal. Mar Ecol Prog Ser 394:277-288.

McNamara J.M. and A.I. Houston. 1996. State-dependent life histories. Nature 380:215-221.
Nagy K.A. and D.P. Costa. 1980. Water flux in animals: an analysis of potential errors in the tritiated water method. Am J Physiol 238:R446-R473.

Oftedal O.T. 1984. Milk consumption, milk yield, and energy output at peak lactation: a comparative review. Symp Zool Soc Lond 51:33-85.

Oftedal O.T., D.J. Boness, and R.A. Tedman. 1987a. The behavior, physiology and anatomy of lactation in the Pinnipedia. Pp. 175-245 in H.H. Genoways, ed. Current mammalogy. Plenum, New York.

Oftedal O.T., S.J. Iverson, and D.J. Boness. 1987b. Milk and energy intakes of suckling California sea lion (Zalophus californianus) pups in relation to sex, growth, and predicted maintenance requirements. Physiol Zool 60:560-575.

Ortiz C.L., D.P. Costa, and B.J. Le Boeuf. 1978. Water and energy flux in elephant seal pups fasting under natural conditions. Physiol Zool 51:166-178.

Ortiz C.L., B.J. Le Boeuf, and D.P. Costa. 1984. Milk intake of elephant seal pups: an index of parental investment. Am Nat 124:416-422.

Pianka E.R. and W.S. Parker. 1975. Age-specific reproductive tactics. Am Nat 109:453-464.

Pomeroy P.P., M.A. Fedak, P. Rothery, and S. Anderson. 1999. Consequences of maternal size for reproductive expenditure and pupping success of grey seals at North Rona, Scotland. J Anim Ecol 68:235-253.

Royle N.J., I.R. Hartley, and G.A. Parker. 2004. Parental investment and family dynamics: interactions between theory and empirical tests. Popul Ecol 46:231-241.

Schmidt-Nielsen K. 1979. Animal physiology: adaptation and environment. 2nd ed. Cambridge University Press, Cambridge.

Speakman J.R. 1997. Doubly labelled water: theory and practice. Chapman \& Hall, London.

Stearns S.C. 1992. The evolution of life histories. Oxford University Press, Oxford.

Testa J.W. 2004. Population dynamics and life history tradeoffs of moose (Alces alces) in south-central Alaska. Ecology 85:1439-1452.

Trites A.W. 1991. Fetal growth of northern fur seals: life-history strategy and sources of variation. Can J Zool 69:2608-2617.

Trivers R.L. 1974. Parent-offspring conflict. Am Zool 14:219261.

Verrier D., R. Groscolas, C. Guinet, and J.P.Y. Arnould. 2009. Physiological response to extreme fasting in subantarctic fur seal (Arctocephalus tropicalis) pups: metabolic rates, energy reserve utilization and water fluxes. Am J Physiol 297:R1582R1592.

Williams G.C. 1966. Natural selection, the costs of reproduction, and a refinement of Lack's principle. Am Nat 100:687-690.

Zuur A.F., E.N. Ieno, and G.M. Smith. 2007. Analysing ecological data. Springer, New York.

Zuur A.F., E.N. Ieno, N. Walker, A.A. Savelieu, and G.M. Smith. 2009. Mixed effects models and extensions in ecology with R. 1st ed. Springer Science and Business Media, New York. 
Copyright of Physiological \& Biochemical Zoology is the property of University of Chicago Press and its content may not be copied or emailed to multiple sites or posted to a listserv without the copyright holder's express written permission. However, users may print, download, or email articles for individual use. 